\title{
NOVICE DESIGNERS TACKLE AND REFLECT ON THEIR PROCESS USING THE DESIGNERLY ACTIVITY THEORY
}

\author{
Tessier, Virginie; \\ Zahedi, Mithra \\ University of Montreal
}

\begin{abstract}
Schön used the metaphor of the swamp and mountain to express the divide between the problems tackled by practitioners and scientists. This research is concerned about the same persisting dilemma between design practice and design theory. In an attempt to discuss this dilemma, we propose to explore research through design (RtD) as a privileged approach where novice designers gain knowledge as practitioners and as researchers. Being aware that RtD approach has received criticisms regarding validity, bias and reliability, we put forward a set of theoretical tools allowing designers to simultaneously proceed with design activity and data gathering processes. To do so, the designerly activity theory framework was presented and explained to two novice designers. They were asked to use the theory's model during an internship project experience, to record their daily actions and later, to proceed with analysis of gathered data. Doing so, we gained a clearer interpretation of the impacts of using a theoretical model as a complement for research through design. We discuss the depth of the participants' reflections, the awareness to less noticeable components, and the enriched dialog between practice and theory.
\end{abstract}

Keywords: Collaborative design, Design theory, Design education, Design process

\author{
Contact: \\ Tessier, Virginie \\ University of Montreal \\ School of Design \\ Canada \\ virginie.tessier@umontreal.ca
}

Cite this article: Tessier, V., Zahedi, M. (2021) 'Novice Designers Tackle and Reflect on their Process Using the Designerly Activity Theory', in Proceedings of the International Conference on Engineering Design (ICED21), Gothenburg, Sweden, 16-20 August 2021. DOI:10.1017/pds.2021.487 


\section{INTRODUCTION}

Design research can be challenging when trying to understand it from the inside. In this paper, we propose to explore how two novice designers navigate between designing a project and researching their collaborative process.

Hebert Simon (1996, p. 111) was an advocate of the sciences of the artificial which he defined by the aim of 'changing existing situations into preferred ones'. His contributions distinguished between artificial outcomes, which relate to what is produced, from the natural sciences, which deal with the state of what already exists. Some years later, Schön (1983), looking at design practitioners, talked about an important gap between theory and practice. He positioned this dilemma by constructing the metaphor of a messy yet easily accessible swamp and the seemingly beautiful and inaccessible mountain. The first is concerned with practical issues of high value to the professionals, while the latter touch on theoretical issues, which are difficult to apply in practice. Schön's dilemma translates a division between theory and practice that we wish to explore with research through design combined with activity theory.

In an attempt to explore how design students make sense of their collaborative work, we want to investigate how the use of activity theory and research through design, together, enhances learning experiences. On the one hand, we aim to better understand how students' understanding of activity theory can facilitate their research through design investigation. On the other hand, we question what are the impacts of such an approach on students' awareness of their interactions, collaborative habits, and co-construction of knowledge? To do so, we conducted an exploratory study that involved two novice designers for six weeks. Students received an introduction to activity theory and a model to facilitate their research through design process leading to greater awareness of collaborative habits.

First, this paper presents research through design and some aspects of the debate surrounding the validity of the approach. Then, we will expose our reflections on integrating activity theory into practice-based research. In the third place, we explain the proposed framework of designerly activity theory and its relevance for the design community. Fourthly, we present the methodological context around the case studies of two collaborating novice designers. Finally, results analysis and discussion are presented by exposing their impacts on design practice, design theory, and design education.

\section{RESEARCH THROUGH DESIGN}

Frayling (1993) reflected on the relation between art, design, and research and proposed a classification of research approaches. He identified three means of linking research for art and design, research into art and design, and research through art and design. In 2004, Findeli adapted these approaches to design. The third approach, research through design (RtD), uses the process of designing for both the design and the research project to create new practical knowledge. It embraces the involvement of the researcher in social science studies. The designer-researcher lays a critical look at its work during and after the project, allowing to reframe the design situation and produce new insights from that process.

In RtD, the resulting artifact(s) confirm the research process accomplished by using in-situ insights to increase our comprehension of the complexity of design (Godin \& Zahedi, 2014). Herriott (2019) illustrated the RtD process as a linear progression between research, object creation, object and process analysis, and production of new knowledge or theory. We emphasize that RtD is not linear, but inherently iterative by alternating between these four stages.

$\mathrm{RtD}$ is a crucial approach for design research as it bridges the gap between theory and practice by valuing action and reflectivity to produce new knowledge. It also ensures authentic outcomes for the design community, while acknowledging the designerly ways of knowing unique to designers (Cross, 2006; Herriott, 2019). Although RtD is meaningful for design, important tensions remain.

First of all, there is no prescribed approach for RtD, which can be good for creative input and navigating ill-defined situations, but less for result validity and comparison. Also, Zimmerman et al. (2010) state that the weak side of RtD is theory development. Their research led to the categorizations of theory on design and theory for design as two potential outcomes of RtD. While the first 'is theory that is developed with the intention of improving the practice of design', the latter 'results from an analysis of artefacts to reveal underlying relationships' (Zimmerman et al., 2010, p. 313). Others have also raised the potential biases of being the central subject of research and its main researcher. On that matter, Manzini (2008) raises the ambiguous level of subjectivity that is acceptable for RtD. While 
subjectivity is often seen as something to avoid in the sciences, it should be taken into account for RtD (Zahedi, 2011). Still, it is unclear to what extent it shifts to bias and risks intervening with the quality of research results. Nonetheless, Jonas (2007, p. 187) confirms the significance of RtD by arguing it 'provides the epistemological concepts for the development of a genuine design research paradigm, which is a condition for methodological development'.

\section{THEORY FOR RESEARCH THROUGH DESIGN}

As presented by Kuhn (1996), theory offers sets of beliefs, basic hypotheses, and ways of seeing reality that supports disciplinary approaches for research, science, and knowledge. These beliefs take form through paradigms that shift over time in agreement with discoveries and new perspectives. By valuing both the design process and design knowledge, RtD has been an important paradigm shift for design research. However, the practice-based theories emerging from RtD are oftentimes questioned, particularly regarding data analysis. In addition to the concerns mentioned in the introduction, 'some designers simply argue that practice is research and practice-based research is, in itself, a form of theory construction' (Friedman, 2003, p. 519). On that matter, Friedman (2003) underlines the contribution of theory for practice, by emphasizing how theory is derived from practice and practice enriched by theory. The author continues by stating that theory has important benefits to organize observations and thinking and to raise doubts about our daily actions. Also, theory leads to the testing of hypotheses in different conditions through generalizations. In Jonas' words (2006, p. 7), RtD offers 'a generic structure of learning/designing, which has been derived from practice'. According to Cash (2018, p. 86), theory is 'the explanation of conceptual relationships in which concepts, constructs, and principles are defined'.

Building on the affirmations of Friedman, Jonas, and Cash, the combination of theory and RtD seems to offer opportunities to answer the various weaknesses that have been raised. Seeking to test this research premise, we opted to investigate activity theory as a potential viewpoint to support RtD in collecting, analysing, and interpreting data. Activity theory and its designerly expansion are explained next.

\section{ACTIVITY THEORY}

In agreement with Cash's definition, activity theory sets conceptual relationships between fundamental elements and guiding principles leading towards systemic analysis. Activity theory (AT) finds its origins in the works of Lev Vygotsky and Alexei Leontiev. The fundamental concepts and principles of the theory have been examined in past design-related publications of the authors (Zahedi et al., 2017; 2018a; $2018 b$ ). These research initiatives have confirmed the potential of the theory for design research to translate the complexity of its process, guide the analysis of actions and gain in-depth insights into social interactions, but -to our knowledge- have never been documented according to RtD.

AT is enriching for research through design and for demystifying the design process for multiple reasons. First of all, both approaches are interventionist as they seek to improve the initial state of a situation by entering an analytic process. In that sense, both objects of these processes are in development. Sannino, concerning her research in the field of education, states that AT is oriented toward change as participants 'reconceptualize the object of their work and invest it with new meaning' (2008, p. 237). Such intention is very similar to that of the design process in which projects gain meaning and take shape through converging constructive cycles. Secondly, RtD and AT both develop from the ground-up. Design thinking and AT studies are initiated with open situations. Moreover, their data gatherings are done in context and they focus on the exploration of current problems. Through these actions, the designer or researcher enriches his comprehension of the initial situation, thus supporting the development of further advancements, gains in quality, or progress. Thirdly, acknowledging that learning occurs through action, RtD and AT favour action for the creation of new, emerging solutions. They are both object-oriented processes 'characterized by ambiguity, surprise, interpretation, sense-making, and potential for change' (Engeström, 2001, p. 134).

AT is based on the concept of mediation, translating the complexity of our interactions with one another and the environment. Another fundamental concept of AT is that of contradiction. Contradictions are perceived as sources of potential changes or development for a system. The identification, study, and discussion of contradictions serve in finding new paths to improve the initial situation. AT, as we know it today, is proposed by Yrjö Engeström (see for example Engeström 1987, 
1999). He introduced the seven-component triangle (Figure 1) with a strong emphasis on the interrelations between the components to translate the complexity of human interactions. The triangle, the components, and the interactions between all components depict the systemic nature of AT. At the top of the triangle, we find the subject-tool-object components which are the initial triad of the theory. These three components translate that a subject's relation with an object is never direct, but always mediated by a third component. The same mediated interaction is found with the subject-rulescommunity or the community-division of labour-object triads.

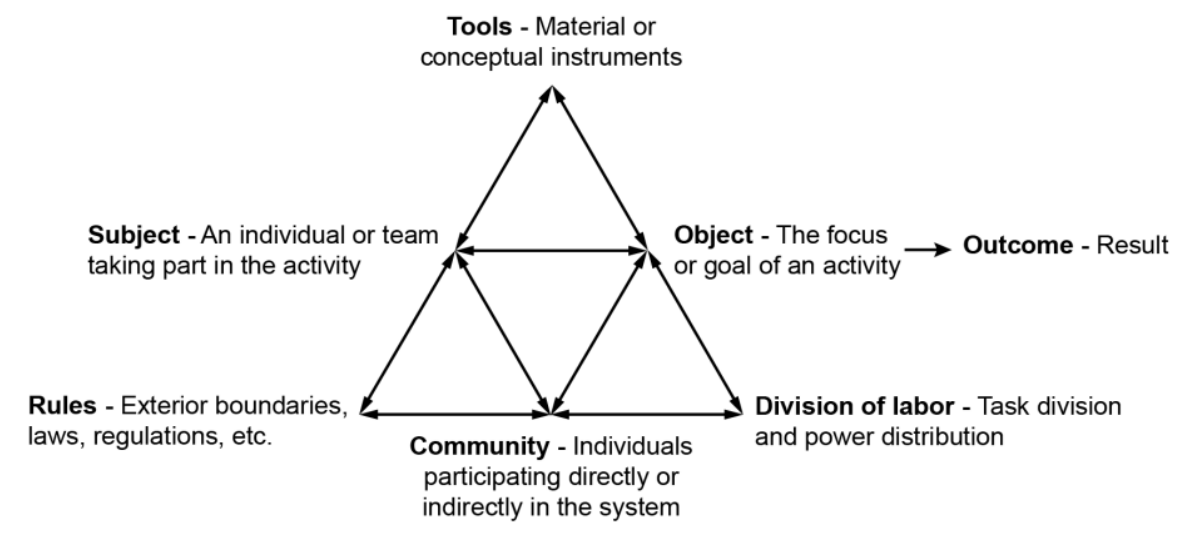

Figure 1. Activity theory model with definitions of components

\subsection{Designerly activity theory}

In our attempts to use AT as a framework to understand the design process, an additional second dimension emerged from the authors' past research (Zahedi et al., 2018a; 2018b). The expansion of the model seeks to build on the systemic nature of the theory to gain a more in-depth analysis of design activities. The designerly activity theory model (d.AT) emerged from the close analysis of design projects, leading to the addition of six components to an external triangle. Figure 2 presents the designerly expansion with brief definitions of each component. Next, we provide short examples of some components.

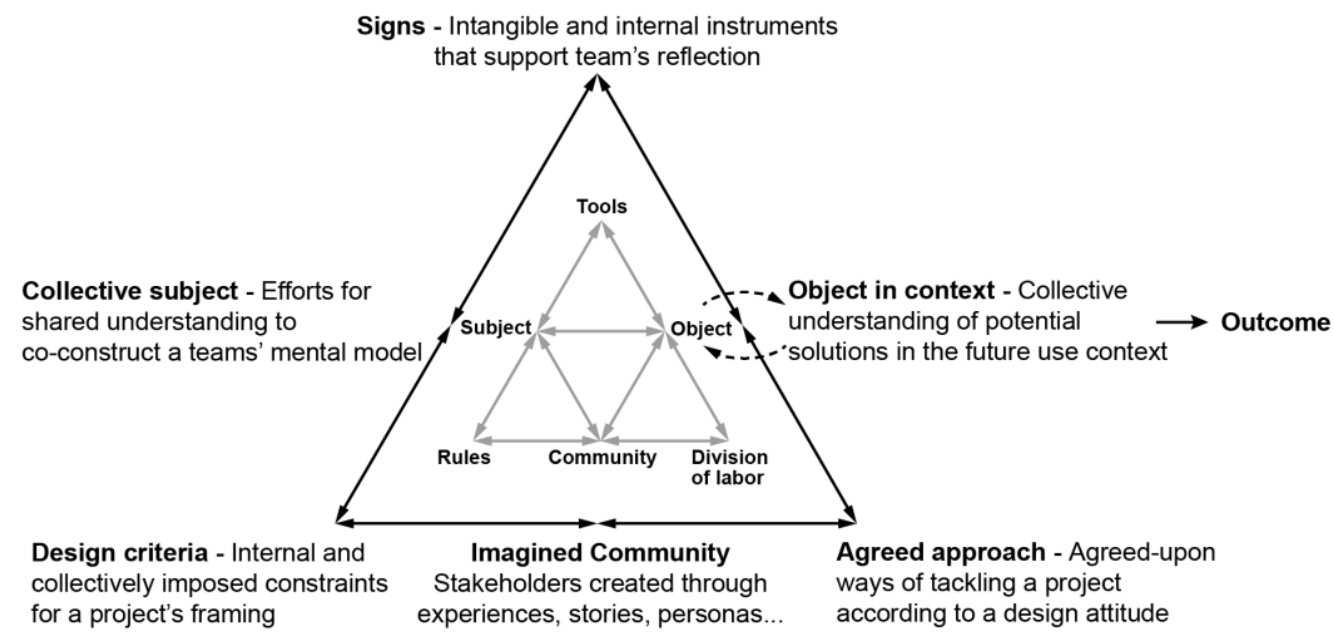

Figure 2. Designerly activity theory model (d.AT) with definitions of additional components

For example, distinctions now exist between the subject and the collective subject. As both components refer to the individuals involved in the activity, the first focuses on the team as a collective of individuals, while the latter concerns the team as a unified entity sharing a common language and a mental model. At the lower-left corner, the components rules and design criteria are also distinguished for greater precision. The rules exist from the start of the project according to the socio-cultural context. They are external to the project (i.e. regulations or standards), while design criteria are internal constraints emerging from the team's shared process (i.e. design decisions). A last example would be the difference between the object and object in context components. Although it is often the case in industrial design, a system's object is not always tangible but can be an abstract concept leading the 
activity. The object in context, however, seeks to conceptualize the object in construction into its potential use context. As design is based on an iterative process, arrows are added between both components to illustrate the process of designing composed of framing, evaluating, and reframing cycles.

\section{DATA COLLECTION}

Going back to the aim of this exploration, prior to data collection, we introduced AT and RtD to the participants -novice designers- to understand how they make sense of their collaborative work. The data collection process was organised to explore the integration and influence of the d.AT model (Figure 2) on the collaborative design experience of the participants. The participants are two design students in their final year of undergrad studies, having no prior professional or RtD experiences. The two participants (P1 and P2) were selected to integrate the research project regarding their interest in design research and motivation to monitor their progression. Also, they were collaborators on the same project for the mandatory internship of their industrial design degree.

Participants integrated a company specialized in interface development. As part of their internship, the team received a mandate to redesign an existing online software offering technological solutions to educators but having major usability issues. The authors of this article did not interfere with the participants' design project. They only provided guidance regarding the potential use of the model during the research and the comprehension of AT theoretical constructs throughout the 6 weeks of their internship. Participants were met by the researchers every 2 weeks to review their logs and clarify or discuss the theory.

More precisely, concerning this study, the participants were asked to report the collaborative events of their design process on a template based on the d.AT model. The template is a blank version of the d.AT model with empty spaces for the participants to annotate information related to the active components of a situation (see Figure 2 as reference or Figure 3 on the left). Prior to the start of the project, the AT and d.AT model expansion were explained to the participants to ensure the optimal use of the template.

Producing daily entries, participants synthesized their activities regarding their design project and their collaboration as a team and with others. They produced over 35 entries each (from one to three logs per week) combining their notes in the d.AT model and additional comments on the template.

After their internship, the two participants were hired as research assistants to analyse the documents they had produced, reflect on their experiences and bring further their RtD process. This work was conducted autonomously by the participants, with weekly feedback from the authors regarding the correct interpretation of the theoretical model. Also, a retrospective interview was conducted between the authors and participants to conclude the project, summarize their experience, and exchange on the use of the template. This interview was informal and focused on the participant's presentation of their analysis and results interpretation. Throughout all the research meetings with the participants, we took note of our observations and monitored the strategies and approaches adopted by the students.

Following this, datasets were exchanged between the participants: P1 analysed P2's data and vice versa. As they both worked on the same project collaboratively, we chose to exchange data between participants to bring an additional layer of co-construction within the team regarding their practices. No clear indications were given to the participants to conduct their analysis, except that they were asked to organize and generate sense of the data based on the d.AT model. As participants were not experienced practitioners nor researchers, they used their intuition to interpret the data.

\section{ANALYSIS OF RESULTS}

As mentioned previously, this paper seeks to focus on two specific aspects of the participant's internship experience: (1) exploring the benefits of theory for a RtD process (2) raising design students' awareness of their collaborative habits. Regarding the exploratory nature of this study, we did not analyse the result of the participants' design project, although we acknowledge that the focus on the object (artifact) is a crucial part of RtD. Based on the participants' analysis process and results, we share three main observations: the challenges and benefits of using the d.AT model as novice designers and researchers, the values and limits of using a template to support note-taking while designing, and the participants' goal-oriented analytic processes. 


\subsection{Use of the d.AT model by novices}

The first insight that emerged from our retrospective analysis of the participants' reported experiences is that the model seems overwhelming at first to an inexperienced person. Although the theoretical concepts of AT can be difficult to grasp, it is only the triangular model and its components that were presented to the participants. Furthermore, they were equipped with the template for the data collection and with a presentation of each component's definitions. Still, both participants expressed troubles and uncertainty regarding which information to classify where in the model. For example, P1 expresses her concerns: 'Having only recently been introduced to the concept of activity theory, some elements of the diagram might seem ambiguous. It was difficult to understand the true scale of the model and the relationships between the different logs as I tried to complete the logbook daily'.

This uncertainty led to challenges regarding the accuracy of the collected data. First of all, as all components were not understood clearly by the participants, they encountered difficulty in identifying tensions within the model. During or after the project, the novices were not apt to emphasize the elements that were in contradiction within their system. As a result, they did the opposite, by identifying which elements were predominant in a situation (Figure 3, diagram on the right).

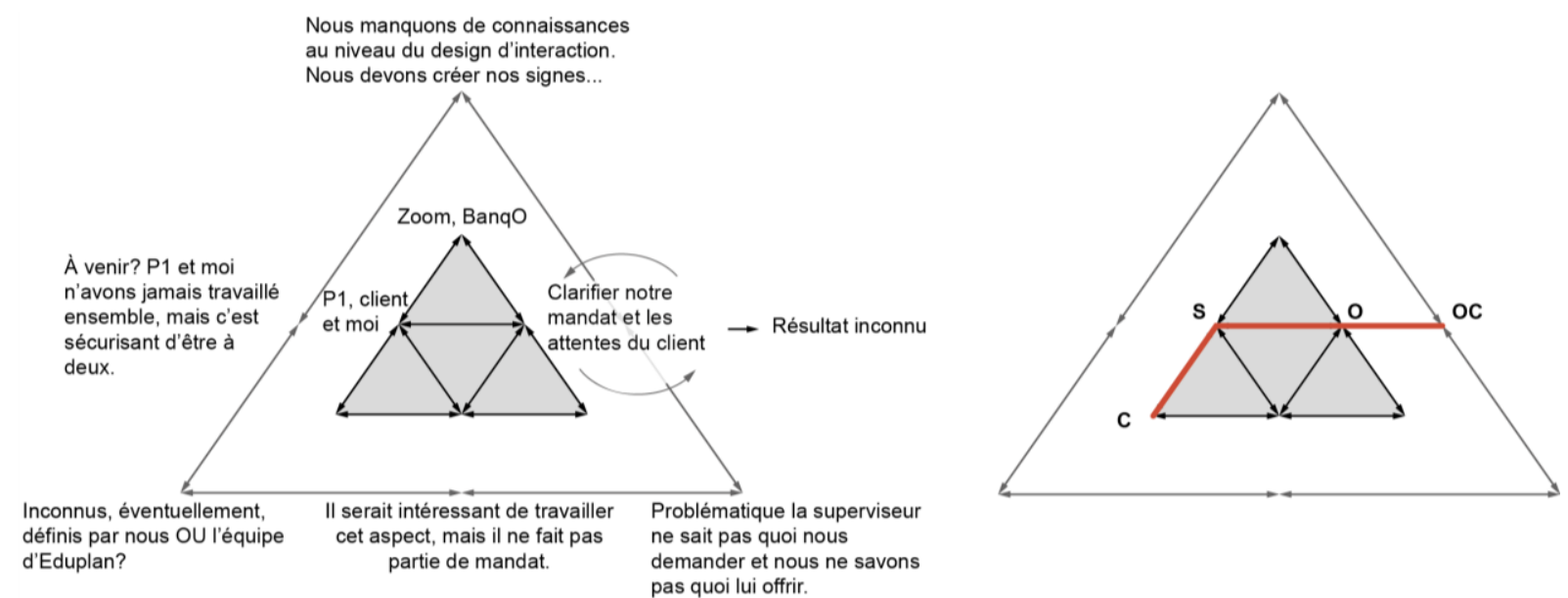

Figure 3. Example of P1's model. On the left, with the initial participant's note (in French), and on the right, the active components schematized after analysis

A second side effect regarding the comprehension of the model led to a first-degree interpretation while conducting the design project. The participants tended to state facts about their activity, making the diagram text-heavy at first. However, as the participants analysed their collaborative process, more in-depth comprehension of the components and reflections allowed more schematic representations of their experience (Figure 3, from left to right). Finally, a third side effect of these doubts regarding the use of the d.AT led to the dominance of the subject/collective subject, tools/signs, object/object in context triad in earlier logs. This observation is meaningful as the upper triad is the first three components of AT, as initiated by Vygotsky. It is noted that the three primary components are easier to understand: themselves or their team, the tools or knowledge they use, and what they are trying to do or in which context. Later interpretations of data translate a better understanding of the model by valuing all components for a more systemic distribution of their input on the activity.

We note that the close collaboration of both participants contributed positively to the depth and progression of their theoretical reflection. As they both worked together on the same design project, they could help each other and seek confirmation: the same collaborative attitude was adopted for the analysis.

\subsection{Note-taking}

The second tendency we identified regarding the use of theoretical tools for RtD regards the structuration of the note-taking process. Instead of writing from their feelings, the template oriented their daily logs in agreement with the d.AT components. Although the initial comprehension of the model seemed confusing to them, the recurrence of its use and the discussions with the research team led participants to feel more confident about their understanding of the model. For example, P2 states: 'The use of triangles made me think more deeply about all the elements involved in my design process 
(the tools used, the people involved, etc.)'. In that sense, the use of theory helps to focus on specific elements of the situation as well as its globality. Still, during the analysis phase, P1 also said she felt confronted with too much information, 'feeling overloaded' and searching for 'a more effective way to vulgarize information'. Through data manipulation and analysis, both participants arrived at multilevelled interpretations of their processes (Figure 4). Participants identified three or more levels in their respective experiences, created links and connections between events and project stages, leading them to reflect more precisely on their project, behaviours, and interactions.

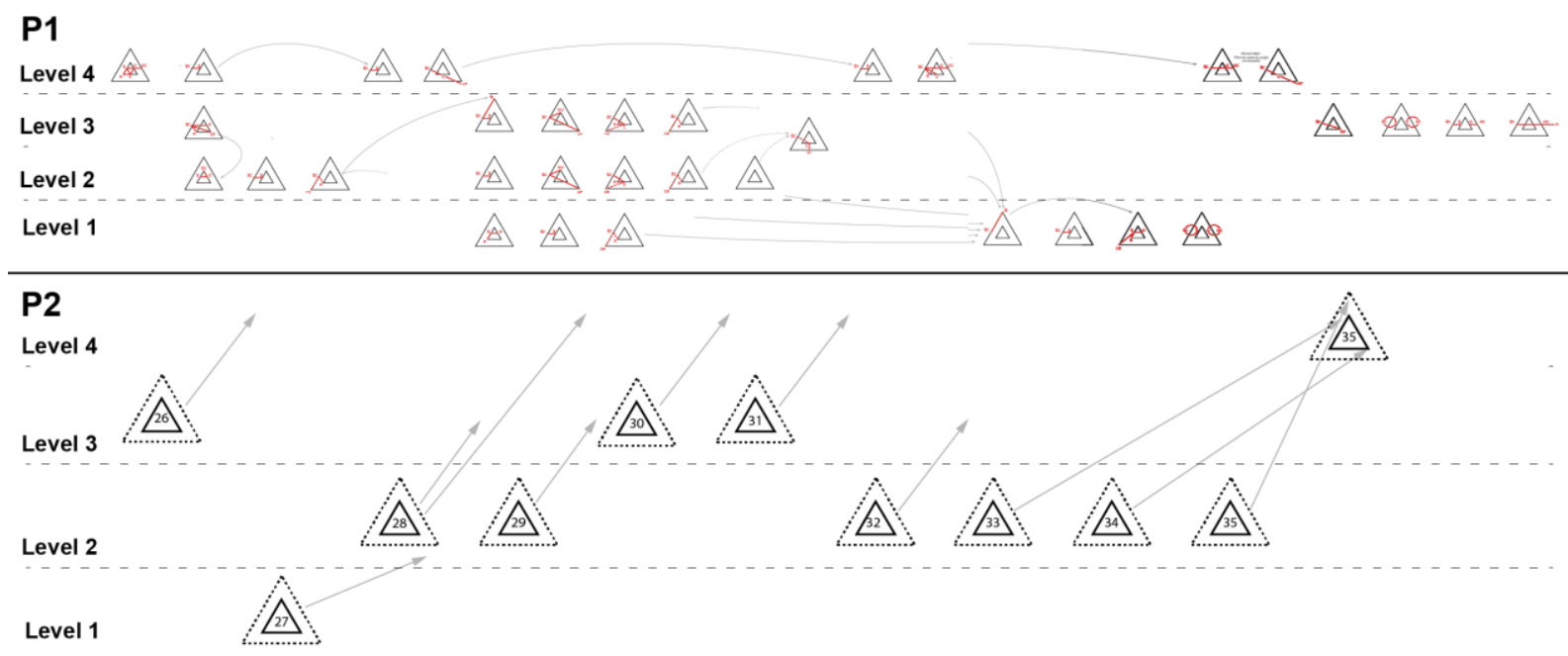

Figure 4. A section of multi-level analysis of participants (top P1, bottom P2)

No templates or instructions were given to participants regarding data analysis. It was their decision, separately, to structure the process on a timeline and in levels. Levels show how tensions and contradictions of one log led to another. Doing so, they searched for patterns. Both participants distinguished, in their own way, between the activity triangle and a more global entity: the project. As their comprehension of the d.AT model grew finer, they reviewed and reworked their daily logs by adding precision to incomplete models or subdividing those that contained too much. As shown in the two graphs of Figure 4, both analyses understand the relations between the triangles as leading to a final objective or outcome, translating a goal-oriented analysis of their project, which is discussed next.

\subsection{Goal-oriented analysis}

Our last observations are related to the authors' witnessing the trial and errors of the two participants during their analyses. From the start, the two participants seemed to use two very different approaches: the first (P1) valuing more a qualitative research design, and the second (P2) leaning on the compilation of graphs, counting repetitions, etc. Both datasets were strictly word-based, but the participants' methods to approach the data were very different. First, P1 adopted a 'micro' attitude towards its dataset, while P2 opted for a 'macro' vision from the start. We observed these tendencies as P1 started to rework all the models of her dataset to gain more confidence about her acolyte's daily logs, while P2 created 5 categories to classify the models in the first week and treated them as groups of data. These different reactions translate different ways to manage this quantity of information, but, ultimately, guided to the similar interpretation of their joint RtD experience.

A major similarity between the participants' approaches is their goal-orientedness. We use the interpretation of $\mathrm{P} 1$ as an example to express how this forward-directed attitude took shape. First, during data collection, P1 said she always initiated her template entries by the outcome: 'The result was seen as a small-scale goal, not the result of the entire internship'. She distinguished between the object of interaction from her perspective, the object in context as perceived by the team, and the outcome as the anticipated result of the interaction. This goal orientation translates to an inclination to take action and move forward in their design project. Another example of this goal-oriented process can be identified in the two diagrams of Figure 4 where most links between activity systems are initiated from the object to another system or level. Moreover, P1's final analysis report translates an especially accurate comprehension of the design process by noticing reframing cycles, project phases, and component interactions for each of these. She identifies four phases in the process after her close 
analysis of her colleague's logbook: (1) introduction of the project, (2) user and object comprehension, (3) redesign and iterations, and (4) follow up on the brief. Model analysis allowed P1 to qualify these phases either as divergent or convergent (phases 1 and 3 are divergent, and phases 2 and 4 , convergent). She explains that phases start or end with drastic changes in the shared approach of the trainees, which in turn creates a crucial change in the object. Then, she identifies seven main activities of the design process, which are distributed around the identified phases. The activities are getting to know, organise, understand the situation, establish constraints, make decisions, divide work, and feedback.

Lastly, the three observations noted from the project and research process of our case study participants seemed to have led to a more structured RtD experience. The two participants were guided by theory during their project, encouraging them to consider all active elements of their system. During the analysis, their comprehension of the d.AT grew and led to precise knowledge on their process, interactions, and interrelations. The following discussion will tackle a few insights we had while analysing their collaborative and theoretical RtD experience.

\section{DIscussion}

Overall, the theory-guided RtD seems to have allowed a greater level of precision, a focus on interactions, and the adoption of a more systemic vision. For example, the two industrial design students that participated in this study's data collection are part of a fifty-student cohort, all of which integrate a company or organization during the same weeks to gain experience from the field. Following their internship, they are asked to submit a document in which they review and reflect on their experience. In this report, most students recall the various events, explain their tasks and responsibilities, identify their challenges and reflect on what they have learned. Still, the participants of this study gained a deeper understanding of their project, process, and skillsets by being encouraged to look at themselves while designing in collaboration. The implantation of d.AT in our participants' experiences may have seemed puzzling at first but had positive repercussions in the end. Building on our observations of the RtD case studies and how participants managed to grow their understanding of theory, we have a few elements to reflect upon: a rigorous data collection, the focus and depths of reflections, the awareness to everyday actions, the systemic view of the process and the enrichment of practice and theory.

The first repercussions relate to the orientation of the object of our participants' reflective thoughts. As most students focus on the solution they have found or created as part of their mandate, the two participants focused on the details of their daily actions, reactions, and interactions, as well as their collaborative process of designing. Therefore, they were encouraged to look and focus on themselves to better understand their habits and behaviours, instead of being centred on the features of the object or interface they created. The materiality of the solution took very little space in the analytic discourse of the participants, leading them to look at their ways of working and interacting instead of being taskfocused all-along. In other words, the seriousness of their analysis with the help of theory led them to increase the granularity of their findings related to their internship experience and design-related knowledge. More specifically, they seemed to acknowledge the collaborative reality of the designer's practice by studying the systemic relations between stakeholders, users, colleagues, etc.

Next, the integration of activity theory in the participants' experience allowed them to make visible elements of the situation that are usually invisible to them. This process of 'visibilization' has been explained by Engeström (1999). He states that visibilization tries to acknowledge practices that are so embedded in a person or a community's ways of doing that they are almost hidden to them. Similarly, third-year students have learned the design process through experience, they developed their habits and best practices, but when confronted to a first professional experience, they are often challenged with their adaptability and capacity to react. Such an awareness to the situation's reaction brings us back to Schön's reflective conversation with the situation: 'In answer to the situation's back-talk, the designer reflects-inaction or the construction of the problem, the strategies of action, or the model of the phenomena, which have been in his moves' (1983, p. 79). As Schön reported, novices are less attentive to these elements and have a more limited repertoire to adequately respond to the situation. For example, Kleinsmann et al. (2012, p. 500) compare students, novices, and experts. The authors contrast the 'degree and quality of knowledge sharing and integration' of these three groups. Their overall observation leads them to conclude that more expertise translates into future-focused goals, as limited experience results in detailcentred analysis or a narrower understanding. They were also more aware of their collaborative habits and mechanisms, which were exposed through their daily logs and further analysis. 
In that sense, the support offered by theory to our participants appears to have led them to develop a more acute sensibility to their habits and the elements of the project, contributing to a stronger bond between practice and theory. Participants constructed their understanding of their project's system through their goal-oriented mindsets. In that sense, the theory-guided case study internship experience seems to have strengthened their interpretation of the relation between theory and practice. The components of d.AT were reinvested in the situation thanks to a refined comprehension of the relations and dimensions. In the end, the use of theory to support a RtD situation could potentially mobilize a deeper level of reflection-on-action as explained by Schön (1986) and fill a gap existing between what designers do, and the constructs they reflect upon. The richness of the theory is both puzzling and intriguing for novices, but it can offer them rigor and structure to overcome challenges, favour reflection-on-action, and set a frame for thinking systemically. For sure, additional case studies are needed to develop further this potential research conclusion. In a way, theory can offer a mirror to the designers, enabling them to enrich and deepen their know-how. Stompff and Smulders introduced the concept of 'mirroring', which translates 'a mirror that shows the consequences of technical choices and enables reflection of these choices' (2013, p. 152). In our case, mirroring was not only technical but overall practical as the two participants achieved to gain an in-depth understanding of their process. The mirror offers precision on the habits and theory offers structure to bring those further. Especially with d.AT, this mirror is adapted to design activities, helping to support a more accurate comprehension of this behaviour. Ultimately, theory mastership could allow autonomy in learning through increased reflectivity on practice.

\section{CONCLUSION}

In conclusion, this paper has allowed us to start a discussion on some of the repercussions of using theory to support the learning experience of novice designers. By raising some questions or doubts directed to RtD as a scientific approach, we also raised some of the benefits that theory can offer to organize thinking, structure actions, and deepen a discourse. In that sense, the participants demonstrated systemic thinking and a focus on their collaborative interactions with their teammate or other stakeholders. As part of this RtD initiative, they established a shared collaboration to build their understanding of the theory and to work on the redesign of an online software.

Although the participants seemed overwhelmed by AT's concepts in the beginning, they were intrigued and managed to create meaning from their own stories. First, theory guided their reflections, structured the analysis of their processes, and led to intelligible practical knowledge. Secondly, they built both a micro and macro vision of their situation allowing for a multi-levelled interpretation of their design activity. Thirdly, they benefited from the dialogue between theory and practice, understanding how theoretical concepts and tools can serve to improve their designerly ways of doing. In the end, we see high potential in the value of theory construction and theory dissemination through approaches that are pertinent and understandable for practitioners.

We are aware that the sample size proposed in this paper is very limited, and only allows for preliminary insights. Still, this exploratory research project is the first of a larger program studying the implementation of research through design and theory in design students' work methodology (other case studies are ongoing). The target population of this study allowed us to start investigating how such a theory-guided experience could contribute to the learners' formation and support their development as reflective practitioners.

In the future, we hope to propose a more in-depth analysis of similar experiences to confirm the insights shared in the paper. We would like to compare our observations of typical RtD processes with theory-guided RtD or reflect on how the d.AT framework can be integrated at various levels of a curriculum. Krippendorff (1989) said that designers gain meaning and generate sense of their task while doing it: this research confirms that the statement also applies to theory, which designers also approach through their iterative process.

\section{ACKNOWLEDGMENTS}

Many thanks to our research assistants and participants, without which this project would not have been possible. Direct citations from participants in the text are free translations by the authors (from French). 
The research project described here has been supported by the Social Sciences and Humanities Research Council of Canada, no. 430-2019-01110.

\section{REFERENCES}

Cash, P. J. (2018), "Developing theory-driven design research", Design Studies, Vol. 56, No. C, pp. 84-119. https://doi.org/10.1016/j.destud.2018.03.002.

Cross, N. (2006), Designerly ways of knowing. London: Springer.

Engeström, Y. (1987). Learning by expanding: An activity-theoretical approach to developmental research. Helsinki: Orienta-Konsultit.

Engeström, Y. (1999), "Expansive visibilization of work: An activity-theoretical perspective", Computer Supported Cooperative Work, Vol. 8, pp. 63-93. https://doi.org/10.1023/A:1008648532192.

Engeström, Y. (2001), "Expansive learning at work: Toward an activity theoretical reconceptualization", Journal of Education and Work, Vol. 14, No. 1, pp. 133-156.

Findeli, A. (2004), "La recherche-projet : une méthode pour la recherche en design", Symposium de recherche sur le design, Bâle, 13-14 May, Swiss Design Network, Swiss.

Frayling, C. (1993), "Research in Art and Design", Royal College of Art Research Papers, Vol. 1, No. 1, pp. 1-5.

Friedman, K. (2003), "Theory construction in design research: Criteria: approaches, and methods", Design Studies, Vol. 24, No. 6, pp. 507-522. https://doi.org/10.1016/S0142-694X(03)00039-5

Godin, D., \& Zahedi, M. (2014), "Aspects of research through design: a literature review", Design's Big Debates, Sweden, 16-19 June, Design Research Society, Umeå, pp. 1667-1680.

Herriott, R. (2019), "What kind of research is research through design?", International Association of Societies of Design Research Conference 2019, 2-5 Sept 2019, IASDR, Manchester School of Art.

Jonas, W. (2007), "Design research and its meaning to the methodological development of the discipline", In Michel, R. (Ed.), Design Research Now: Essays and Selected Projects, Birkhäuser Verlag AG, Basel, Boston, Berlin, pp. 187-206.

Jonas, W. (2006). "Research through DESIGN through research - a problem statement and a conceptual sketch". Design Research Society International Conference, Lisbon, Portugal.

Kleinsmann, M., Deken, F., Dong, A. and Lauche, K. (2012), "Development of design collaborative skills", Journal of Engineering Design, Vol. 23, No. 7, pp. 485-506. https://doi.org/10.1080/09544828.2011.619499.

Krippendorff, K. (1989), "On the essential contexts of artifacts or on the proposition that 'Design is making sense (of things)'", Design Issues, Vol. 5, No. 2, pp. 9-39.

Kuhn, T. S. (1996), The structure of scientific revolution, University of Chicago Press, Chicago.

Manzini, E. (2008), "New design knowledge", Design Studies, Vol. 30, No. 1, pp. 4-12. https://doi.org/10.1016/j.destud.2008.10.001.

Sannino, A. (2008), "From talk to action: Experiencing interlocution in developmental interventions", Mind, Culture, and Activity, Vol. 15, pp. 243-257. https://doi.org/10.1080/10749030802186769.

Savic, S. and Huang, J. (2014), "Research through design: What does it mean for a design artifact to be developed in the scientific context?", STS Italia Conference, Milan, 12-14 June, STS Italia, pp. 1-16.

Schön, D. A. (1983), The reflective practitioner: How professionals think in action. New York: Basic Books.

Simon, H. A. (1996), The sciences of the artificial. Cambridge: MIT Press.

Stompff, G., \& Smulders, F. (2013), "Mirroring: The boundary spanning practice of designers", In C. de Bont, E. den Ouden, R. Schifferstein, F. Smulders, \& M. van der Voort (Eds.), Advanced Design Methods for Successful Innovation, Design United, Eindhoven, p. 144-163.

Zimmerman, J., Stolterman, E. and Forlizzi, J. (2010), "An analysis and critique of research through design: Towards a formalization of a research approach", ACM Conference on Designing Interactive Systems, Aarhus, August, ACM Press, Denmark, pp. 310-319. https://doi.org/10.1145/1858171.1858228.

Zahedi, M. (2011), Modèle novateur de conception d'interface humain-ordinateur centrée sur l'utilisateur: Le designer en tant que médiateur, Ph.D., Université de Montréal.

Zahedi, M., Tessier, V., \& Hawey, D. (2017), "Understanding collaborative design through activity theory". The Design Journal, Vol. 20(Sup 1), pp. 4611-4620. https://doi.org/10.1080/14606925.2017.1352958.

Zahedi, M., \& Tessier, V. (2018a), "Designerly activity theory: Toward an ontology for design research" Catalyst, Ireland, 25-28 June, Design Research Society, Limerick, pp. 319-333.

Zahedi, M., Tessier, V., \& Heaton, L. (2018b), "Designerly Activity Theory insights on the design processes of a Korean company", Design Thinking Research Symposium, 15-16 Dec, DTRS, Ulsan. 